\title{
WALLENBERG PRICE 2006
}

\author{
The Editorial Board of Annals of Forest Science is proud to publish the acceptance speech of \\ Antoine Kremer, who was awarded with the Wallenberg Price at Stockholm during October 2006
}

\section{DIVERSITY: THE DRIVING FORCE OF SUSTAINABILITY AND EVOLUTION}

\author{
Antoine KREMER \\ UMR INRA-Université de Bordeaux “Biodiversité, Génétique, Écologie” (BioGEco), Domaine de Pierroton, 33612 Cestas Cedex, France; \\ E-mail: Kremer@pierroton.inra.fr
}

First of all I wish to thank the Marcus Wallenberg Foundation for the high honour of selecting me as the 2006 winner of the Marcus Wallenberg Prize. Receiving this prize in the country of Carl von Linné adds to the tribute I feel, and to the gratitude I would like to express towards the Foundation.

Carl von Linné is obviously an interesting link between the place where we are today and the research that is awarded. Not only because he was the first to name the oak "Quercus" and to identify the few oak species growing in Europe, but also because he was the very first to start the endless task of inventorying biological diversity on earth. The research awarded is a minor piece in this monumental task, as it concerns only oaks. But for the very first time, the inventory took place at the most intimate level where diversity resides: at the DNA level. I would like to comment on the broader issues and implications, encompassing both species and societies, to which diversity leads.

I am particularly thankful to the Foundation and the Selection Committee for recognizing the achievements in a research area that does not result in readily "identified" short term benefits. "Population genetics and evolution" has long term interests and looks at changes within species that accumulate over evolutionary times. However, time has all of a sudden accelerated. We hear daily on the news that environmental change will occur at rates that have never occurred before. And the question is obviously raised about how organisms and particularly trees will cope with these changes. These predictions and the concerns that they raised demonstrate how relevant research in evolutionary biology is today.

In this respect, knowledge of past evolution may be valuable information for predicting future responses. This is why the reconstruction of the postglacial history of oaks on a paneuropean scale has attracted the attention of policy makers, scientists, and I guess the members of Marcus Wallenberg Prize Selection Committee.
As biologists, we know that evolution is going on, but we do not know at this point where it will go. In addition we do not know today the needs and services that society expects from forests in the future. These expectations are likely to change over time as well. What will the needs be in hundred years from now?

Oaks are certainly a good example of the constantly new and different services that these species have provided to mankind: from food to shelters, from cathedral to ships, from firewood to beams, from tannins to ink, and today from carbon sink to veneer. So there are two uncertainties we have to deal with: the environmental (ecological) uncertainty of what the forests will be and the economical and societal expectations of forest products. How can evolutionary sciences address uncertainty in order to "meet the needs of the present without compromising the needs of future generations"?

The answer is in diversity. If we are able today to preserve the diversity of life, we will increase our capacity to respond to these changes.

Diversity has therefore become a central focus in recent years. Not only in biology but also in various other areas, social sciences, economy or even politics. In any one of these domains, diversity is referred to as a necessary resource for sustainability:

- in biology, diversity will ensure adaptation of individuals and species to future conditions;

- in social sciences, cultural and linguistic diversity, while stimulating respect for cultural identity, is a central pillar for peace, harmony and cultural sustainability;

- in economy, globalization has been considered recently as a threat to economic equilibrium, and has been opposed to the maintenance of heterogeneous local economies. 
To sum up, diversity is not a neutral scientific concept. It is directly linked to stability (of systems, whether biological, social or economic. Hence diversity has become a major issue in species and societies, in terms of research and policy.

Interestingly, it has some intriguing similarities across these different domains:

First of all Diversity is a Heritage. In biological species, diversity is generated by mutation, and accumulates over generations as mutations are transmitted by reproduction and gene flow. Talking about oaks, our investigations have clearly shown how immense this diversity is and how trees have developed mechanisms preventing erosion of diversity. Just to illustrate the reservoir of diversity. When you compare the genetic differences between two oak trees taken at random in a forest, with two human individuals taken at random in a city or this audience, you will find out that there is four times more diversity in trees then in humans. These figures clearly illustrate how oaks, and trees in general, have accumulated diversity during their history.

One can also observe the accumulation of diversity in our social systems, as a result of political history and transmission of knowledge over generations.

Secondly Diversity is a Resource, in economic terms. The nicest illustration is shown in domesticated plants or animals, where genetic selection has virtually extracted from the natural species, the various properties man can make use of. About 20000 species are used worldwide for producing medicines and food. In social systems, one can as well note that multiethnic or multicultural societies may generate greater wealth and benefits.

Third, Diversity is a warranty for an uncertain future. I have already mentioned how in a world of ecological and economic uncertainty, diversity may be the safeguard for future adaptation to environments and response to new demands. In agricultural and forestry systems, there are various reports showing how the maintenance of multispecific cultures contributes to higher protection against pests and diseases, hence preventing ecological and economical disasters.

In social systems, there is less evidence. But one could easily argue that ancient and extremely sophisticated civilizations (Maya, Aztec, Inca... ) became extinct because of the lack of cultural and ethnical diversity.

Since biological diversity was actually recognised as such by the term biodiversity in the seminal work by Wilson in 1988, since the first inventories were conducted, it became clear that Biodiversity is facing severe threats, due to various human and natural interferences. There are reports that about $1 \%$ of the living species become extinct every year, that before the end of this century half of the living species will have disappeared, that the actual extinction rate is about 1000 times higher then the average extinction rate that is recorded across ages.

\section{Who is concerned by our nice concept of diversity?}

On one hand scientists almost continuously release technical reports warning about the sixth extinction crisis that life is experiencing. On the other hand politicians meet regularly in international conferences to discuss worldwide actions to be taken. And this process has been repeatedly going on for several years, with no clear long term strategy emerging to solve the problem.

I will not join the voices of the Cassandra and predict a planet catastrophe or add to the on going noise. I would rather question: why is it that the voices of scientists do not reach the ears of our politicians? Is there anything wrong with science? What has science still to demonstrate to convince policy makers about actions to be taken?

Of course there have been in recent years a number of crises where science has been in the forefront and indirectly accused of misbehaviour: Mad cow disease, AIDS scandals, GMOs. The public, the media have become suspicious of the opinions and predictions of scientists.

As science is - so to speak - weak, other principles or concepts are being advocated for policy issues, not necessarily based on solid evidence. If this situation continues, it may lead to extremely controversial and dubious positions in policy-making in a number of areas related to biology and starting with our own area in forestry and biodiversity. Indeed, foresters and managers refer more and more frequently to "close to nature" practices rather then implementing measures coming from experimental studies.

\section{Where is science today?}

Science should take a more active role and address challenging issues related to biodiversity, instead of concentrating on more conservative approaches. Taking global change as an example, a large part of research activities is being dedicated on conservation projects, partly because funding is more easily available when you pinpoint the risk of extinction. However from an evolutionary point of view, global change is likely to accelerate evolution and generate new assemblages of species and diversity. This is a new area of investigations, where science is only poorly involved, despite the promising challenge it represents. And this is where research and science should play a more proactive role.

The challenge of research in our area is not in conservation. The challenge is in evolution.

Finally, as a conclusion, we need to get science fully into its place in our society, and this is the time for reconciliation between science and the public. And to my opinion, there are a few reasons why research in biodiversity and evolution has the potential to achieve this.

First of all, measuring and understanding diversity is a challenge for our own AND the future generations.

We have heard not earlier than last week in the media that the whole genome of a tree species was recently totally sequenced. But this was only for one given tree. We are just at the onset of the expectations that this achievement has lead to. If we intend to continue the work of Carl von Linné and make 
the inventory of diversity at the DNA level as we started during the past years, then an immense task opens for the future generations.

\section{Second, biodiversity research generates a vision and goal for our future.}

I have tentatively tried to illustrate why diversity is intimately related to sustainability. As more diversity is discovered and inventoried, we will understand how these relationships get established, and how they can be adjusted in the future to preserve our resources and those of future generations.

Third and as a more personal opinion and feeling, biodiversity research fulfils at least partially the anxiety and angst that one may be exposed to as scientist or just as a human being. Any biological problem or question translates sooner or later into an evolutionary issue. "Why is it so, is there any evolutionary reason?" These are also questions we are raising in reference to our own life. And as such science helps somehow to answer our personal queries.

At least this was my personal motor or driver that helped me to conduct the research on the evolutionary biology of oaks in Europe. Of course there were a number of other motors and actors that contributed to this success story, and I would like to thank all the many colleagues, personal friends and institutions for their contributions to this twenty years research work which was awarded. 